\title{
THE DEVELOPMENT OF TEACHING GUIDELINE AND INTERACTIVE NUTRITION EDUCATION MODULE FOR PRIMARY SCHOOL TEACHER
}

\author{
Muhammad Aries $^{1 *}$, Hana Fitria Navratilova², Khoirul Anwar ${ }^{3}$, and Hardinsyah Hardinsyah ${ }^{4}$ \\ 1,2,4 Department of Community Nutrition, Faculty of Human Ecology, Bogor Agricultural University \\ ${ }^{3}$ Nutrition Study Program, Faculty of Food Technology and Health, Sahid University - Jakarta \\ *ariesulaeman@ipb.ac.id
}

\begin{abstract}
Healthy eating and daily active lifestyle is important for good health and development of school children, who are vulnerable to malnutrition which can disrupt their learning process and school achievement. On the other hand, the primary school teachers and parents can play an important role in the education and promotion of healthy eating and active lifestyle for the children. The aim of this community service program was to develop a teaching guideline and interactive nutrition education (TG-INE) module for primary school teachers. This activity was held on January - August 2018 in Bogor Agricultural University. The steps of this activity included: 1). Establishment of technical working group (TWG); 2). Review the existing nutrition education module for primary school students; and 3). Development of teaching guideline and interactive nutrition education module for teacher. The component in the TWG which were formed consists of school principals, nutrition professional society (Food and Nutrition Society of Indonesia), university staffs (Bogor Agricultural University and SAHID University Jakarta), and local government (Bogor Education Office). The TWG developed nine topics for TG-INE module, namely balance diet and my plate; active and healthy life; cereals, fruit and vegetable; protein food; limit sugar salt and fat; choosing safe and nutritious food; food label; and summary. The TG-INE module was designed colourfully and interestingly. Prior to the final version TG-INE module, it was assessed to be used by selected school teachers. In conclusion, the TG-INE module could be used by primary school teachers to educate their students on healthy eating and active lifestyle.
\end{abstract}

Keywords: interactive module, nutrition education, school teacher, teacher guideline.

\section{Introduction \\ Background}

Students aged 9 (nine) years are at a period of continued growth and development after the preschool age period. According to Weichselbaum and buttriss (2011), children at this age are vulnerable in experiencing problems of food, nutrition and health, such as malnutrition, nutritional anemia, diarrhea, upper respiratory tract infections, and dental carries. Furthermore, Indonesian school children also face the overweight and obesity as part of the double burden of nutrition where the prevalence of this problem in 2011 is 11.5\% (Sandjaja et al. 2013). All of these problems finally can interfere in their learning process and school achievement (Prado and Dewey 2014; Sudfeld et al. 2015). These problems are attributed to the lack of knowledge and practice of clean and healthy lifestyle, limited capability of teachers in the food areas, nutrition and health education, lack of sanitation infrastructure and facilities, unsafe food sold in the canteen or by vendors around the school, and lack of cooperation across the perpetrator (Smith and Haddad 2015). This shows the need of nutrition education with better approach.

The school children is a strategic target of health and nutrition education. In addition, the nutrition education itself plays an important role in health and nutritional status of school children 
because can contribute directly to improving knowledge, practice and nutrition behaviors in daily life (Sherman and Muehlhoff, 2007; Kostanjevec et al. 2011).

Perez-Rodrigo and Aranceta (2003) and Porter et al. (2018) stated that schools are a wellorganized institution and viewed as effective settings for preventative nutrition education efforts targeting children due to their reach and structure. Reason for this statement is because schools are the natural development zone for nutrition education. They are one of the main social contexts in which lifestyles are developed (FAO, 2005). In Indonesia, particularly the primary schools have the school health program (Usaha Kesehatan Sekolah/UKS) and The Little Doctor (Dokter Kecil) which the main objective is to increase the quality of education by protecting the pupils health and providing them with a good environment so that they can focus on learning. One of their activities scope is health and nutrition education. However, program implementation varies among schools as these are located in different areas, municipalities, and provinces and make their contribution to nutrition and health status of pupils still not optimal (SIREP, 2016).

The need of effective nutrition education model become urgent because there is orientation movement from knowledge to behavioral orientation. Previous research showed that improvement in knowledge and attitudes do not usually go side by side with positive changes in practice (Perez-Rodrigo and Aranceta, 2001; Contento et al. 2002). Incorporating nutrition topics through an interactive nutrition education program in the primary school curricula should support the acquisition of nutrition knowledge in different ways and indirectly the development of healthy eating habits in school children. This nutrition education program for school children conducted by teachers with utilising a specially designed teaching guideline and interactive nutrition education modules.

\section{Objectives}

The main objective of this community service program was to develop a teaching guideline and interactive nutrition education (TG-INE) module for primary school teachers. Furthermore, there are some specific objectives which are: 1) to emphasize the importance of improving nutrition knowledge of school children to the health and education authorities; and 2) to improve children's knowledge, attitude \& practice (KAP) on diet \& physical activity.

\section{Method}

The Step of Activities

Overall, the program consist of 3 (three) activities: 1). Establishment of technical working group (TWG); 2). Review the existing nutrition education module for primary school students; and 3). Development of teaching guideline and interactive nutrition education module for teacher. Furthermore, the development of teaching guideline and interactive nutrition education module divided into 3 (three) parts: selecting the school for module implementation, developing of the module, and field testing the developed module.

Time and Locations

The program will be implemented as one years in 2018. The preparation stage (establishment of technical working group and review the existing nutrition education modules for primary school students) conducted in 2017. The program carried out in SDN Gunung Batu 1 and SDN Gunung Batu 2, Bogor, West Java, Indonesia. 

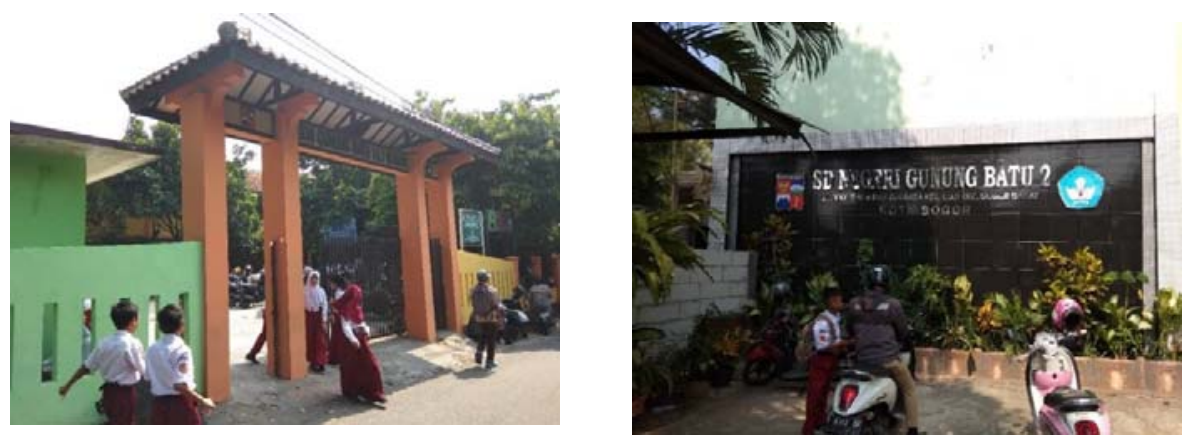

Figure 1. Target Schools (Gunung Batu 1 and Gunung Batu 2 Primary School

\section{Result and Discussion}

Emphasise the Importance of Multi Sectors Collaboration to Improve Nutritional Knowledge of School Children

Primary schools are particularly suitable environment for nutrition education. They catch children when their habits are still being formed and the habits including the eating habits and physical activities. Children of school-going age develop behavior through interaction with other pupils, teachers, parents, siblings and peer groups. Besides that, they are influenced by their homes, their communities, the mass media - and the school. Thus the school is part of a network of influences which shape eating patterns, attitudes and physical activities habits (FAO, 2005). Furthermore, there are some reasons that primary schools are ideal setting for health and nutrition education: cchool reach most children at a critical age when eating habits and attitudes are being established, have responsibility to guide young people including through nutrition education, have qualified personnel to teach and guide, school can establish school policies and practices that can improve health and nutrition, school also can spread the effect by involving families in their children's nutrition education, and can be a channel for community participation which include young people, school staff, families and community members (Aldinger \& Jones,2005; FAO, 2005).

According to Perez-Rodrigo and Aranceta (2003) in health promoting school approach, schoolbased nutrition education should consider the needs and interests of students, teachers and the school. This means that all the groups meeting in the school setting should be invited to become relevant stakeholders in the project (Figure 2).

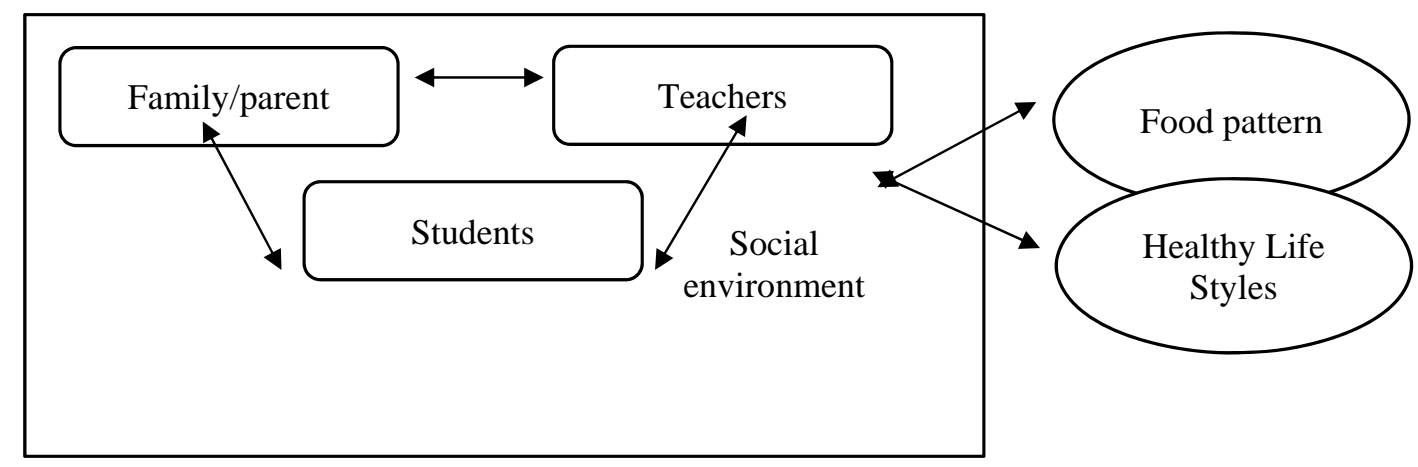

Figure 2. School-based nutrition education: interactions between actors and environmental conditions (Source: Perez-Rodrigo and Aranceta (2003)

The emphasis on environmental and behavioural factors in successful school-based physical activity and nutrition education highlights the importance of involving parents and other community members. Parents can take part in the school should be encouraged (Perez-Rodrigo and Aranceta, 2003). In line with previous statement, SIREP (2016) stated that the factor considered to be most crucial to the 
successful implementation school health programs in primary schools are effective collaboration between government agencies and strong partnership with different stakeholders. Therefore, in order to achieve the first specific objective of this program, the technical working group (TWG) of this program were established with the composition of group consist of PERGIZI PANGAN Indonesia (represent the professional societies), Department of Community Nutrition, Faculty of Human Ecology, Bogor Agricultural University (represent the academic societies), the principal and teachers from target schools, and Southeast Asia Public Health Network (SEA-PHN).

\section{Selection of Schools and Teachers}

The first step for school selection is TWG invite the collaboration of 2 schools to be part of the programme. Previously, the TWG get an approval and recommendation letter from Bogor Educational Office No. 421.2/2.7.37 - SD. In the invitation there are statements that the schools must agree on the involvement of several key teachers in the programme and school must agree for these teachers to carry out during lessons in classroom (eg physical education lesson/starting of each class).

The criteria in choosing the primary schools are: 1) public primary schools, 2) having students more than 200 students, 3) agreed upon the local government, and 4) the schools (the principles and the parent association chair) commit to participate. From each of the schools, at least two teachers and every principal/head master will be recruited and trained on nutrition and health (9 selected nutrition education topics). Teachers that involved in this program are the $4^{\text {th }}$ grade teacher since the the primary target group of this program are primary school children 9-10 years old while parents and teachers become the secondary targets

\section{Developing and Producing Moduls}

Prior to developing and customization the educational media/kits, the TWG conducted a review of the problems of nutrition and health of the primary school children. The TWG also reviewed the previous nutrition education model and interactive modules. This review used as a basis for developing enriching materials of the relevance subjects and developing educational materials/Kits.

The educational media/kits then developed in form of teacher guide book, folding cards, game cards, and parent leaflets. The urban primary school children are likely familiar with advance information and technology, however the availability and accessibility of that technology such as DVD player and computer in every class is not possible. Therefore a combination of traditional and modern media and technology could be developed. There are nine (9) topics of nutrition education that selected: The healthy way of eating: from pyramid to plate; Be active be healthy; Cereals, cereal products, and tubers for energy; Veggies and fruit for health; Protein foods make you grow stronger; Limit fats, sugar, and salt for health; Choose safe and healthy foods especially when eating out; Use food labels for healthier food choices; and Review: eat smart and be active. The example of educational media, teaching guideline and interactive nutrition education module that developed presented at Figure 3. 


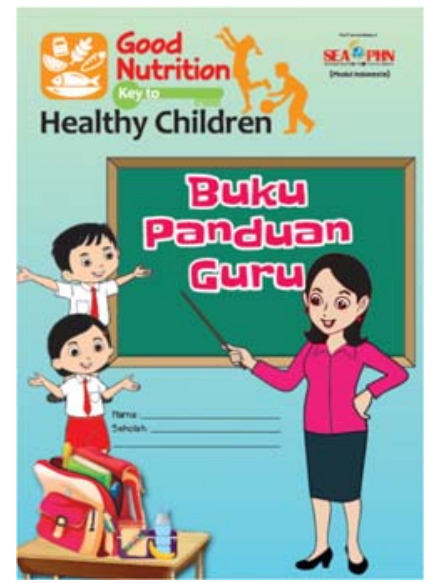

a. Teachers
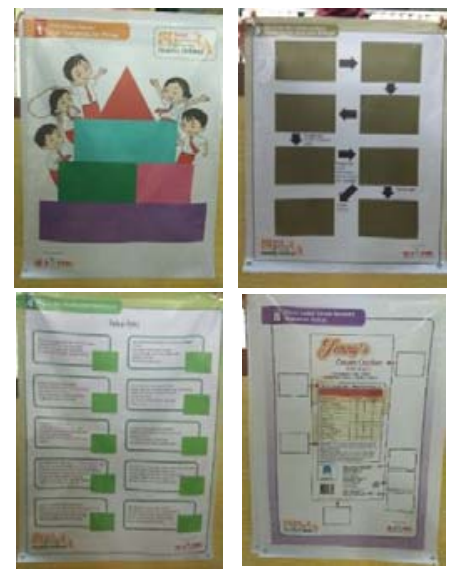

b. Folding cards

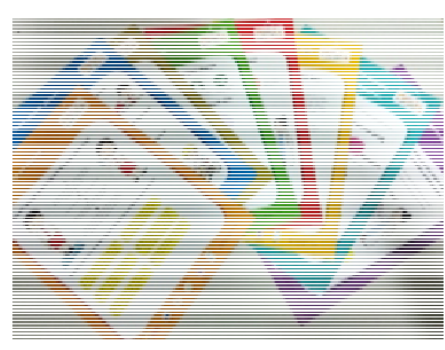

c. Parent leaflets

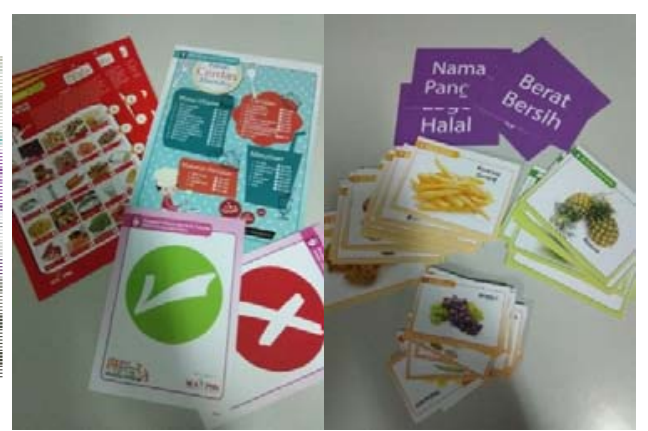

d. Game cards

Figure 3. Teaching Guideline and Interactive Nutrition Education Module

\section{Implementation: Roll-out of nutrition education in school by trained teachers}

There are 10 selected primary school teachers and 2 principals from school target who follow the training of interactive nutrition education module. This training conducted in Training of trainers (multi stage training) setting. The materials of the training includes: the program and management, roles of teachers and parents, role of schools and parent association, how to deliver the enriching materials, how to use the education media/kits, success and failures factors of the program, reward, and action plan of each of the school. Trainer for the school teachers are nutritionist (member of PERGIZI PANGAN Indonesia) and lecturer from Department of Community Nutrition, Faculty of Human Ecology, Bogor Agricultural University. The initial field testing of interactive nutrition education conducted during the training with the selected teachers as the user. The training activities and field testing to teachers presented in Figure 4.

The selected school teachers who trained by nutritionist and lecturer instructed to conduct pre lesson KAP (knowledge, attitude, and practice) survey and body mass index (BMI) assessment before the start of 1st topic and to conduct post-lesson KAP survey and BMI assessment after the $8^{\text {th }} / 9^{\text {th }}$ topic. Timeline for implementation of whole topics/module arranged at the second day of training. During the training, the nutritionist also explain that there will be visitation and monitoring when lessons being conducted by teachers from time to time. Teachers required to fill up monitoring evaluation form (e.g: date and no of session conducted, no of students attend per session, provide feedback on students receptiveness towards the session and modules) and to send photos in conducting the activities. 


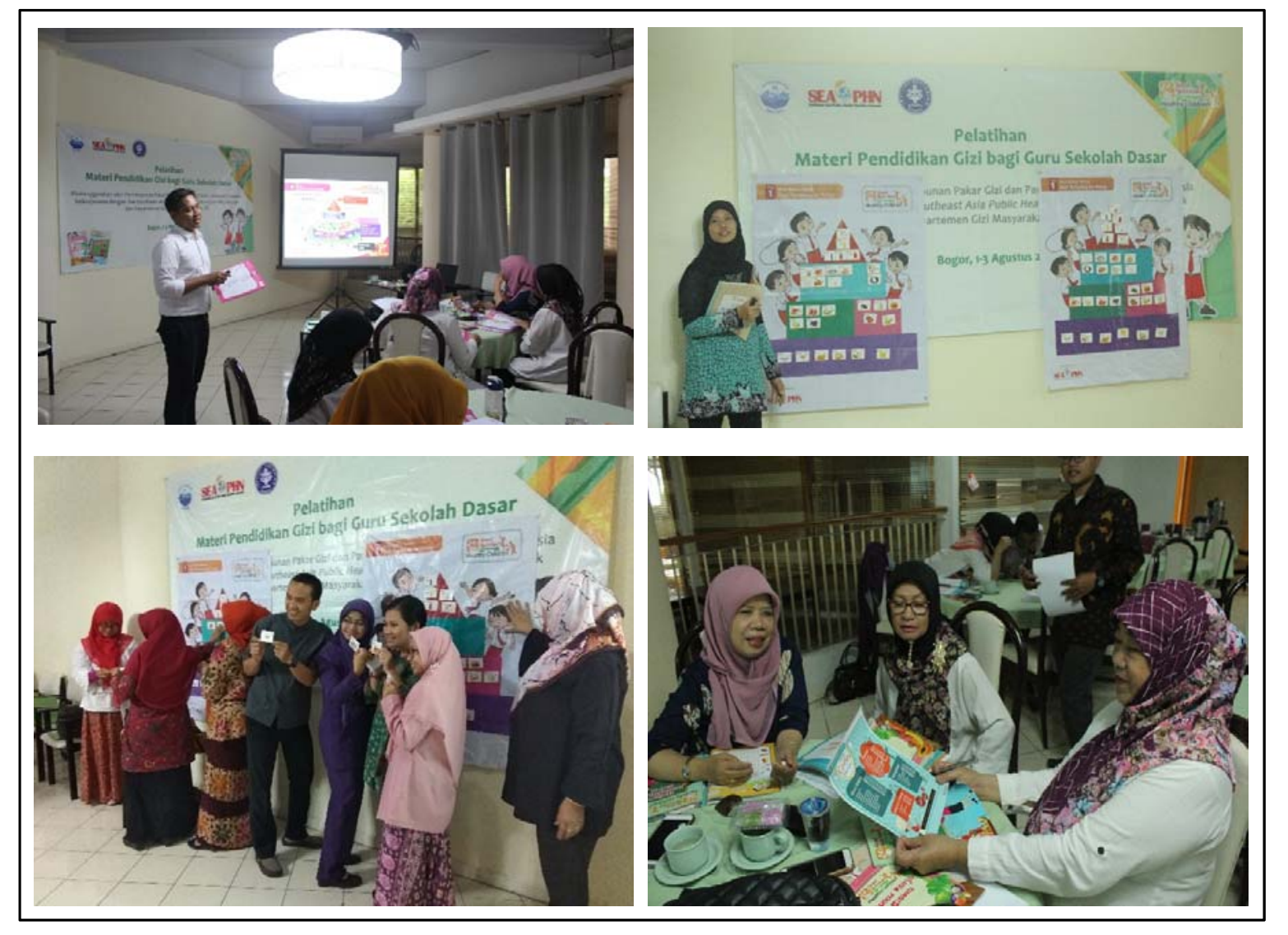

Figure 4. Test and Assessment of Developed Teaching Guideline and Interactive Nutrition Module by Selected School Teachers

Prior to the implementation, a set of key performance indicators formulated based on the inputprocess-output framework of the program. Based on that, a simple questionnaire of monitoring developed to be used by the principal every two months to monitor the progress of the program, and discuss feedback at school.

The program will be implemented for 3 to 4 months and during the implementation, every school will be assisted by the technical working group. The major role of the assistantship is facilitating and helping schools (teachers) in implementing the plan of action to achieve the objective of the program. Furthermore, the role of the assistantship also to monitor and give feedback of the implementation of the program. The TWG will compile the KAP results (both pre and post lessons), BMI assessment data and teacher monitoring evaluation forms to write the overall report.

Through this program, at least in the initial phase there are increasing of awareness, knowledge, and behaviour of the school children. Sherman and Muehlhoff (2007) stated that for this kind of program, the Initial results suggest that gains in awareness, knowledge and behavior can be achieved among children and their families with an actively implemented classroom program backed by teacher training and parent involvement, even in the absence of school-based nutrition and health services.

\section{Conclusion}

The emphasis on environmental and behavioural factors in successful nutrition education in school is importance of involving parents and other community members. Multi sectors collaboration considered to be most crucial factor to the successful implementation school health programs. 
The educational media/kits that developed in form of teacher guide book, folding cards, game cards, and parent leaflets and the expected result from implementation of this kind of module at initial phase are increasing of awareness, knowledge, and behaviour of the school children.

\section{References}

Aldinger CE \& Jones JT (1998): Healthy Nutrition: An Essential Element of a Health-promoting School. WHO Information Series on School Health. Document four. Geneva: WHO.

Contento IR, Randell JS, Basch CE. (2002). Review and analysis of evaluation measures used in nutrition education intervention research. $J$ Nutr Educ Behav. 2002;34:2-25.

FAO. (2005). Nutrition Education in Primary Schools, Volume 1: The Reader. Rome, Italy. www.fao.org/docrep/pdf/009/a0333e/a0333e00.pdf

Kostanjevec S, Jerman J, Koch V. (2011). The Effects of Nutrition Education on 6th graders Knowledge of Nutrition in Nine-year Primary Schools in Slovenia. Eurasia Journal of Mathematics, Science \& Technology Education, 7(4): 243-252

Perez-Rodrigo, C. and J. Aranceta. (2001) School-based nutrition education: lessons learned and new perspectives. Publ Health Nutr. 2001;4:131-139.

Perez-Rodrigo, C. and J. Aranceta (2003). "Nutrition education in schools: experiences and challenges." Eur J Clin Nutr 57 Suppl 1: S82-85.

Porter KJ, Koch PA, Contento IR. (2018) Why and how schools make nutrition education programs “"work.” J Sch Health. 2018;88: 23-33

Prado EL, Dewey KG. (2014). Nutrition and brain development in early life. Nutrition reviews, 72(4): 267-284.

Sandjaja, Poh BK., Rojroonwasinkul, N., Le Nyugen, B.K., Budiman, B., Ng, L.O. et al. (2013). Relationship between anthropometric indicators and cognitive performance in Southeast Asian school-aged children. (Epub 2013/09/18. PubMed PMID: 24016767). Br J Nutr. 2013; 110: S57S64 https://doi.org/10.1017/S0007114513002079

Sherman J and Muehlhoff E. (2007). Developing a Nutrition and Health Education Program for Primary Schools in Zambia. J Nutr Educ Behav. 2007;39:335-342

SIREP (SEAMEO INNOTECH Regional Education Program). (2016). School Health Care and Nutrition in Primary Schools in Southeast Asia: Policies, Programs, and Good Practices. SEAMEO INNOTECH, Commonwealth Ave., Diliman, Quezon City, Philippines. https://www.seameoinnotech.org/wp-content/uploads/2016/10/SHN-Report-2015.pdf

Smith LC, Haddad L. (2015). Reducing child undernutrition: past drivers and priorities for the postMDG era. World Development, 68: 180-204.

Sudfeld CR, McCoy DC, Fink G, Muhihi A, Bellinger DC, Masanja H, Smith ER, Danaei G, Ezzati M, Fawzi, WW. (2015). Malnutrition and Its Determinants are Associated with Suboptimal Cognitive, Communication, and Motor Development in Tanzanian Children-3. The Journal of nutrition, 145(12): 2705-2714.

Weichselbaum E, Buttriss J. (2011). Nutrition, health and school children. Nutrition Bulletin, 36(3): 295-355. 